\title{
Cost-utility analysis of germline BRCA1/2 testing in women with high-grade epithelial ovarian cancer in Spain
}

\author{
Carlota Moya-Alarcón ${ }^{1} \cdot$ Almudena González-Domínguez² ${ }^{2} \cdot$ Susana Simon ${ }^{1} \cdot$ Inés Pérez-Román $^{2}$. \\ Antonio González-Martín ${ }^{3,4}$. Eloisa Bayo-Lozano ${ }^{5}$. Ana Beatriz Sánchez-Heras ${ }^{4,6}$
}

Received: 13 September 2018 / Accepted: 21 December 2018 / Published online: 8 January 2019

(c) The Author(s) 2019

\begin{abstract}
Purpose Germline mutations in BRCA1 and/or BRCA2 genes (gBRCA1/2m) are associated with an increased risk of breast cancer (BC) and ovarian cancer (OC). The aim of this study was to estimate the efficiency of providing germline BRCA1/2 testing to high-grade epithelial ovarian cancer (HGEOC) patients without family history of OC or BC and the subsequent testing and management of their relatives with gBRCA1/2m in Spain.

Methods/patients Incident HGEOC patients without family history of OC or BC who were gBRCA $1 / 2 \mathrm{~m}$ carriers and their relatives were simulated in a 50-year time horizon. The study compared two scenarios: BRCA1/2 testing vs no testing, using the perspective of the Spanish National Health Service. Cancer risk among gBRCA1/2m carriers was estimated based on their age and whether they had undergone risk-reducing surgeries. Direct healthcare costs and utilities of patients who developed EOC and BC were also included. A probabilistic sensitivity analysis (PSA) with 5 thousand simulations was developed considering $\pm 25 \%$ of the base-case value.

Results The BRCA1/2-testing scenario amounted to $€ 13,437,897.43$ while the no-testing scenario amounted to $€ 12,053,291.17$. It was estimated that the screening test improved the quality of life among the patients' relatives by 43.8 quality-adjusted life years (QALYs). The incremental cost-utility ratio (ICUR) was $€ 31,621.33 / \mathrm{Q} A L Y$ in the base case. The PSA showed that $89.12 \%$ of the simulations were below the $€ 50,000 / \mathrm{QALY}$ threshold.

Conclusion Providing this screening test to HGEOC patients and their relatives is cost-effective and it allows one to identify a target population with high risk of cancer to provide effective prevention strategies.
\end{abstract}

Keywords Ovarian cancer $\cdot$ BRCA1 gene $\cdot$ BRCA2 gene $\cdot$ Cost-utility analysis · Quality-adjusted life years · Cancer screening test

Electronic supplementary material The online version of this article (https://doi.org/10.1007/s12094-018-02026-2) contains supplementary material, which is available to authorized users.

Almudena González-Domínguez

almudena.gonzalez@weber.org.es

Carlota Moya-Alarcón

Spain.HealthEconomics@astrazeneca.com

Susana Simon

susana.simon@astrazeneca.com

Inés Pérez-Román

ines.perez@weber.org.es

Antonio González-Martín

agonzalezm@seom.org

Eloisa Bayo-Lozano

eloisa.bayo.sspa@juntadeandalucia.es

Ana Beatriz Sánchez-Heras

sanchez_ana@gva.es
1 AstraZeneca Farmaceutica Spain, 56, Serrano Galvache Street, Building Álamo, 28033 Madrid, Spain

2 Weber, 17, $5^{\circ}$, Moreto Street, 28014 Madrid, Spain

3 Clínica Universidad de Navarra, 1, Marquesado de Santa Marta Street, 28027 Madrid, Spain

4 Grupo Español de Investigación en Cáncer de Ovario (GEICO), 151, Santa Engracia Street, Floor 5, Office 3, 28003 Madrid, Spain

5 Plan Integral de Oncología de Andalucía, Servicio Andaluz de Salud, Hospital Juan Ramón Jiménez, Ronda Exterior Norte, 21005 Huelva, Spain

6 Unidad de Consejo Genético en Cáncer, Hospital General Universitario de Elche, 11, Camino de la Almazara, 03203 Elche, Spain 


\section{Introduction}

Ovarian cancer (OC) is the fifth most frequent cancer among women in Spain [1]. In 2017, a total of 3412 new cases of OC were diagnosed [2], most of them with epithelial origin (EOC) $(87.3 \%)$. Recent research has shown that $71.3 \%$ of the patients suffer high-grade EOC (HGEOC), which grows steadily and is diagnosed at advanced stages (III and IV) [3]. Like breast cancer (BC), OC is related to germline mutations in BRCAI and/or $B R C A 2$ genes (gBRCA1/2m) $[4,5]$. The average cumulative risks by the age of 70 for $B R C A 1$-mutation carriers were $60 \%$ for $\mathrm{BC}$ and $59 \%$ for OC, while the corresponding risks for $B R C A 2-$ mutation carriers were $55 \%$ for $\mathrm{BC}$ and $16 \%$ for $\mathrm{OC}[6]$.

In 2011, the Spanish Society of Medical Oncology (SEOM) guidelines established the eligibility criteria to offer genetic testing to gBRCA $1 / 2 \mathrm{~m}$ carriers with hereditary cancer. Genetic testing should be offered to OC patients, taking into account age at diagnosis, family history of $\mathrm{BC}$ and/or OC, and diagnosis of BC in male relatives [7]. However, Alsop et al. [8] showed that $74.8 \%$ of patients with HGEOC had no family history of $\mathrm{BC} / \mathrm{OC}$ and that $8.3 \%$ of patients without family history were gBRCA $1 / 2 \mathrm{~m}$ carriers. Those results are in accordance with the recently updated guideline (SEOM 2015), which establishes that all patients with non-mucinous HGEOC should be offered germline BRCA1/2 testing, regardless of family history of OC or BC [9].

Being identified and informed of gBRCA $1 / 2 \mathrm{~m}$ status of $\mathrm{BC}$ or OC patients and their relatives allow one to develop cancer-prevention strategies in a target population with high risk of cancer [7, 9]. Risk-reducing surgeries such as bilateral salpingo-oophorectomy (BSO) and/or bilateral mastectomy $(\mathrm{BM})$ are the most effective methods to reduce the risk of developing BC and/or EOC [10]. In BRCA1-mutation and $B R C A 2-$ mutation carriers, $\mathrm{BSO}$ decreased the risk of developing $\mathrm{BC}$ in $49 \%$ and $61 \%$, respectively, and the risk of developing EOC in $84 \%$ and $88 \%$, respectively. Likewise, BM reduced the risk of developing $\mathrm{BC}$ in $90 \%$ and $91 \%$ of the patients, respectively, and both surgeries reduced the risk of BC in $95 \%$ of the patients [11].

According to SEOM 2015 guidelines, it was recommended to extend the population to provide germline BRCA1/2 testing to those patients with no family history of $\mathrm{OC}$ or $\mathrm{BC}$. Therefore, the aim of this study was to estimate the efficiency of providing this screening test to non-mucinous HGEOC patients without family history of $\mathrm{OC}$ or BC and the subsequent testing and management of their relatives with gBRCA1/2m in Spain.

\section{Materials and methods}

An individual-level simulation with annual cycles was originally developed for the United Kingdom and was adapted to the Spanish health care setting, using Microsoft Excel ${ }^{\circledR}$ [11]. The perspective was that of the Spanish National Health Service and the time horizon was 50 years. The simulation results were costs and quality-adjusted life years (QALYs), and the incremental cost-utility ratio (ICUR) was estimated.

\section{Data sources}

Epidemiology data, survival rates, cancer risks, healthcare resources use and utilities were obtained from a literature review, including national and international references (the latter were used whenever national data were not available). Databases consulted were Medline/Pubmed, Embase, Medes, American Economic Association's Electronic Bibliography (EconLit) and other official databases. All extracted data were contrasted and validated by a multidisciplinary expert group. The methodology consisted in one individual online survey, an in-person meeting, and a meeting conducted via telephone to reach final consensus. The expert group was composed of three oncologists: one specialised in OC, one accredited by SEOM to provide genetic counselling for hereditary cancer and one specialised in radiation oncology in charge of the oncology plan in Andalusia region in Spain.

\section{Population}

The simulation was initiated with incident non-mucinous HGEOC patients without family history of OC or BC (initial population). It was considered that the average age at the diagnosis of those patients is $51 \pm 5$ years [12]. After undertaking germline BRCA1/2 testing, those patients who were gBRCA1/2m carriers (index population) were simulated, along with their first-degree relatives. When first-degree relatives had gBRCA1/2m, second-degree relatives were also included (Fig. 1, Tables 1, 2). Patients and relatives with $\mathrm{gBRCA} 1 / 2 \mathrm{~m}$ transitioned to various health states (no cancer, EOC, BC, EOC and BC, and death) at the beginning of every annual cycle.

\section{Risk of developing BC or EOC}

As this is an individual-level simulation, it takes into account the previous events of each patient. Cancer risk among gBRCA1/2m carriers was estimated based on their age and whether they had undergone risk-reducing surgery (RRS). It was considered that $65 \%$ and $25 \%$ of gBRCA $1 / 2 \mathrm{~m}$ carriers 


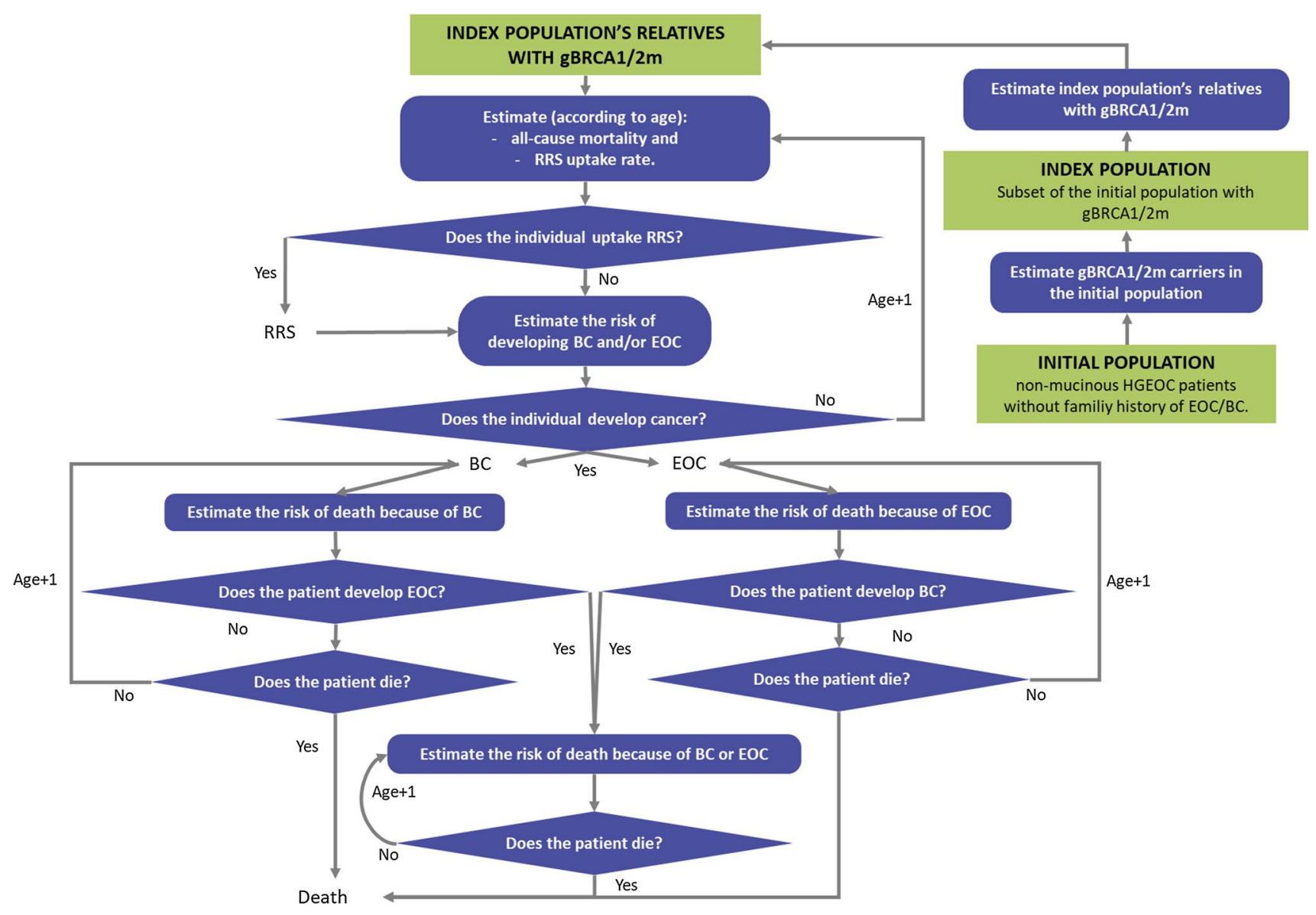

Fig. 1 Simulation diagram.

$B C$ breast cancer, $g B R C A 1 / 2 m$ germline mutations in BRCA1 and BRCA2 genes, HGEOC high-grade epithelial ovarian cancer, $R R C$ risk-reducing surgery. Dark rectangles show the estimations related to the simulated population, shown in light rectangles. Diamonds show the decisions or paths that the simulated population may take. Created by Microsoft Office
Table 1 Characteristics of the initial population and their relatives

\begin{tabular}{llll}
\hline & Data inputs & $\begin{array}{l}\text { Number of } \\
\text { patients }\end{array}$ & References \\
\hline Patients with OC & 3412 & 3412 & {$[2]$} \\
Patients with non-mucinous HGEOC (\%) & 62.2 & 2122 & {$[3]$} \\
Patients with non-mucinous HGEOC without family history of & 74.8 & 1588 & {$[8]$} \\
$\quad$ BC/OC (initial population) (\%) & & & \\
Initial population with gBRCA1/2m (index population) (\%) & 8.3 & 130 & {$[8]$} \\
gBRCA1m (\%) & 66.8 & 87 & {$[5]$} \\
gBRCA2m (\%) & 33.2 & 43 & {$[5]$} \\
\hline
\end{tabular}

References: SEOM [2], Matz et al. [3], Alsop et al. [8], and Rebbeck et al. [5]

$O C$ ovarian cancer, HGEOC high-grade epithelial OC, gBRCAlm germline mutations in BRCAl gene, gBRCA2m germline mutation in BRCA2 gene accepted to go through BSO and BM, respectively [13]. The risk of developing EOC and/or BC among the gBRCA1/2m carriers that underwent RRS is shown (Table 1, Online Resources). When an individual developed cancer, the risk of developing a secondary cancer (BC or OC) was also estimated.
Each year, the simulation determined whether the simulated population died because of BC or OC until they reached their age of all-cause mortality. The 5-year survival rates of $\mathrm{BC}$ and $\mathrm{OC}$ by age have been previously studied (Table 1, Online Resources) [14]; whenever a secondary cancer appeared, a new mortality rate was used. The 
Table 2 Characteristics of the relative population

\begin{tabular}{|c|c|c|c|c|c|}
\hline First degree & Mother & Father & Siblings & Children & References \\
\hline Number of first-degree relatives, mean $\pm \mathrm{SD}$ & 1 & 1 & $0.7 \pm 0.3$ & $1.5 \pm 0.5$ & {$[15]$} \\
\hline Age relative to index population (years), mean $\pm \mathrm{SD}^{\mathrm{a}}$ & $27.8 \pm 2.0$ & $30.1 \pm 2.0$ & 2.4 & $-27.8 \pm 2.0$ & [15] \\
\hline Gender, probability female & $100.0 \%$ & $0.0 \%$ & $48.3 \%$ & $48.3 \%$ & [16] \\
\hline Probability of mutation in $B R C A 1$ or $B R C A 2$ genes & $50.0 \%$ & $50.0 \%$ & $50.0 \%$ & $50.0 \%$ & [16] \\
\hline Second degree & Grandparents & Uncles/aunts & Nephews/nieces & Grandchildren & \\
\hline Number of second-degree relatives, mean \pm SD & 4 & 1.4 & 1.1 & 2.4 & {$[15]$} \\
\hline Age relative to index population (years), mean \pm SD & $27.8 \pm 2.0^{\mathrm{b}}$ & $2.4^{\mathrm{b}}$ & $-27.8 \pm 2.0^{\mathrm{c}}$ & $-27.8 \pm 2.0^{\mathrm{d}}$ & [15] \\
\hline Gender, probability female & $50.0 \%$ & $48.3 \%$ & $48.3 \%$ & $48.3 \%$ & [16] \\
\hline Probability of mutation in $B R C A 1$ or $B R C A 2$ genes & $25.0 \%$ & $25.0 \%$ & $25.0 \%$ & $25.0 \%$ & [16] \\
\hline
\end{tabular}

References: Spanish Statistical Office [15] and Petrucelli et al. [16]

${ }^{\text {a }}$ Simulated individuals were assigned their age according to the age distribution of the index population

${ }^{\mathrm{b}}$ The age of grandparents and uncles/aunts was estimated according to the age of the parents

${ }^{\mathrm{c}}$ The age of nephews/nieces was assessed in relation to the age of the siblings

${ }^{\mathrm{d}}$ The age of grandchildren was calculated based on the age of the children

all-cause mortality rates were those of the Spanish general population [15].

\section{Resource use}

Healthcare resources use was that recommended in the SEOM 2015 guideline [9], according to the following scenarios:

1. BRCA1/2-testing scenario includes genetic counselling (one visit and a germline BRCA1/2 test), RRS, surveillance (one annual magnetic resonance imaging (MRI) and one annual mammography, along with one biannual transvaginal ultrasound and one biannual CA125 test), cancer management and palliative care.

2. No-testing scenario includes cancer management for the index population and their relatives that developed BC and/or EOC and palliative care.

Cancer management included treatment, hospitalisations, emergency visits and follow-up tests.

The simulation considered that the genetic counselling and CA125 tests were provided to the initial population and index population's relatives. Moreover, as $10 \%$ of gBRCA $1 / 2 \mathrm{~m}$ are due to large gene rearrangements, a large rearrangement analysis was also taken into account for $10 \%$ of the initial population and $10 \%$ of their relatives [16].

When an individual developed cancer, treatment costs were considered and the risk of developing a secondary cancer (BC/OC) was assigned. It was assumed that female relatives who went through a preventive BM but developed $\mathrm{BC}$ would not have undergone surgery as a part of their cancer management. However, surgical therapy was considered for those women who developed EOC, even though they had undergone BSO.

Palliative care was given to EOC and BC patients in their last 48 days [17] and 43 days [18], respectively. It was assumed that up to $93.3 \%$ of the patients would receive follow-up care at outpatient hospitals by a nurse, while the remaining $(6.7 \%)$ would be attended by palliative home care services [19]. In both cases, patients would need an average of 0.15 follow-up visits. Patients would also need 0.07 visits to the primary care physician [17]. Up to $40.4 \%$ of the cancer patients would spend their last days at the hospital (on an average of 15.16 days for EOC patients and 13.35 days for BC patients) $[20,21]$. The remaining $(59.6 \%)$ would spend their last 3 days at home [22], where they would be visited twice a day by a nurse, and $14 \%$ would receive sedation [22, 23]. The simulation also included palliative care received by individuals that do not die because of BC and/or EOC. It was assumed that palliative care is given to those patients in their last 3 days and that they use the same resources than $\mathrm{BC}$ and/or EOC patients.

\section{Costs}

Costs were expressed in 2017 Euros (Table 2, Online Resources). Unit costs of germline BRCA1/2 testing, genetic counselling, CA125 test, and most of the surgeries were imputed in the model as the median values of these unit costs for all autonomous communities in Spain [24] and were applied in the year when they occurred. Costs of BM and hospitalizations were collected from the database of the Ministry of Health, Social services and Equality (CIE9MC) [20]. Since the original costs came from different sources, they were updated using the Consumer 
Price Index for medical care in the case of direct healthcare costs (except for pharmaceutical costs and tariffs from autonomous communities already updated) [15]. Future costs were discounted at an annual rate of $3 \%$, according to Spanish health technology assessment recommendations [25].

The cost of EOC management was previously estimated in the Ovarcost study. The average annual cost per patient was $€ 17,067$ and $€ 15,042$ with and without surgical therapy, respectively [26]. As the survival rate for BC is higher than the one registered among EOC patients, the simulation applied the cost of $\mathrm{BC}$ management in the first year after the diagnosis [11]. The cost of BC treatment [chemotherapy, radiology, hormone therapy (anastrozol) and surgery] was estimated based on the patient distribution [27] and the cost per patient by stage at diagnosis [28]. The simulation also took into account the hormone therapy for $\mathrm{BC}$ patients who had undergone BSO during 5 years. Other direct healthcare costs were estimated based on Luengo et al. [29]. Study $[11,30]$ (Table 3, Online Resources). The average annual cost per patient of BC management was estimated to be in $€ 27,249.51$ and $€ 23,337.60$ with and without surgical therapy, respectively (Table 3, Online Resources).

Palliative care costs were applied in the year of the patient's death, and were $€ 3648.39$ per EOC patient and $€ 3522.13$ per BC patient. The average cost of all-cause palliative care was $€ 274.42$ per patient.

\section{Utilities}

The simulation included the utilities of the healthy relatives and those who developed EOC and BC. It was assumed that, after a cancer diagnosis, health state utility worsened in the following years until year 6; afterwards, health state utility remained constant [31-34]. When patients developed a secondary cancer, utility values were multiplied. The impact of RRS on health state utility of the study population was applied in the year the surgery occurred [35-37] (Table 4, Online Resources).

\section{Sensitivity analysis}

A one-way sensitivity analysis was carried out to examine the simulation's robustness in which the most relevant parameters. A probabilistic sensitivity analysis (PSA) was also conducted, including five thousand simulations of the cohort. Most parameters were independently varied by either a 95\% confidence interval (CI) or by clinical expert opinion; when no estimates were available, values were varied by $\pm 25 \%$ of the corresponding base-case value (Table 5, Online Resources).

\section{Results}

The study population included 130 women with gBRCA1/2m (index population), and 104 first-degree and 19 second-degree relatives ( 71 gBRCA $1 \mathrm{~m}$ carriers and 52 gBRCA2m carriers). Our results showed that providing germline BRCA $1 / 2$ testing for 50 years would decrease the number of EOC cases from 8 to 6 and $\mathrm{BC}$ cases from 20 to 7. Besides, the number of deaths due to those cancers would decrease from 88 to 83 . Therefore, germline BRCA1/2 testing improves disease-free survival in those cancers.

Table 3 shows the costs in both scenarios. As BRCA1/2testing scenario included the cost of genetic counselling, RRS, and surveillance, it was costlier than the no-testing scenario. However, the costs associated with the cancer management of patients' relatives were lower in the BRCA1/2testing scenario compared to the no-testing scenario. The difference between both scenarios was $€ 781,813.20$ among patients and $€ 602,793.06$ for patients' relatives.

The global cost of providing germline BRCA1/2 testing over 50 years to HGEOC patients without family history of EOC and BC were estimated in $€ 13,437,897.43$, while the no-testing scenario accounted for $€ 12,053,291.17$. As a result, the difference between both scenarios was $€ 1,384,606.26$ (Table 3).

The simulation estimated 2107.8 QALYs in the BRCA1/2-testing scenario and 2064 QALYs in the no-testing scenario. We concluded that the screening test resulted in an increase in patients' relatives' QALYs by 43.8. Therefore, the ICUR associated with the introduction of this germline BRCA1/2 testing was $€ 31,621.33 / \mathrm{Q} A L Y$ (Table 3).

\section{Sensitivity analysis}

The results of the one-way deterministic analysis are shown in Table 4. As can be seen, the results vary from $€ 14,692.37$ to $€ 37,596.55$. The PSA showed that all simulations were in the upper-right quadrant of the cost-effectiveness plane. The ICUR ranged from $€ 17,366.59 / \mathrm{Q} A L Y$ to $€ 291,254.29 /$ QALY. The resulting cost-effectiveness plane is shown in Fig. 2a. The willingness-to-pay curve is shown in Fig. 2 b.

\section{Discussion}

This study estimates the cost-utility of providing germline BRCA1/2 testing in HGEOC patients without family history of OC or BC. This knowledge allows identifying their BRCA1/2-positive relatives, to offer them strategies for cancer prevention. Our results showed that providing germline BRCA1/2 testing over 50 years to those patients and 
Table 3 Healthcare costs and QALYs of initial and index population

\begin{tabular}{|c|c|c|c|}
\hline Parameters & No testing & BRCA $1 / 2$ testing & Difference \\
\hline \multicolumn{4}{|l|}{ Costs $(€)$} \\
\hline \multicolumn{4}{|l|}{ Patients: initial population } \\
\hline Testing & 0.00 & $761,525.4$ & $761,525.4$ \\
\hline Genetic counselling visits & 0.00 & $20,287.8$ & $20,287.8$ \\
\hline Bilateral mastectomy & 0.00 & 0.00 & 0.00 \\
\hline Bilateral salpingo-oophorectomy & 0.00 & 0.00 & 0.00 \\
\hline Hormone replacement therapy & 0.00 & 0.00 & 0.00 \\
\hline Surveillance & 0.00 & 0.00 & 0.00 \\
\hline \multicolumn{4}{|l|}{ Patients: index population } \\
\hline Epithelial ovarian cancer management & $10,527,260.7$ & $10,527,260.7$ & 0.00 \\
\hline Breast cancer treatment & $342,915.1$ & $342,915.1$ & 0.00 \\
\hline Palliative care & $408,833.4$ & $408,833.4$ & 0.00 \\
\hline Total cost & $11,279,009.2$ & $12,060,822.4$ & $781,813.2$ \\
\hline \multicolumn{4}{|l|}{ Relatives } \\
\hline Testing & 0.00 & $30,980.1$ & $30,980.1$ \\
\hline Genetic counselling visits & 0.00 & $187,767.4$ & $187,767.4$ \\
\hline Bilateral mastectomy & 0.00 & $98,900.9$ & $98,900.9$ \\
\hline Bilateral salpingo-oophorectomy & 0.00 & $297,229.9$ & $297,229.9$ \\
\hline Surveillance & 0.00 & $291,974.5$ & $291,974.5$ \\
\hline Epithelial ovarian cancer management & $391,302.1$ & $319,178.7$ & $-72,123.4$ \\
\hline Breast cancer treatment & $337,553.1$ & $125,473.4$ & $-212,079.8$ \\
\hline Palliative care & $45,426.8$ & $25,570.4$ & $-19,856.4$ \\
\hline Total cost & 774,282 & $1,337,075.1$ & $602,793.1$ \\
\hline \multicolumn{4}{|l|}{ Global } \\
\hline Testing & 0.00 & $792,505.5$ & $792,505.5$ \\
\hline Genetic counselling visits & 0.00 & $208,055.2$ & $208,055.2$ \\
\hline Bilateral mastectomy & 0.00 & $98,900.9$ & $98,900.9$ \\
\hline Bilateral salpingo-oophorectomy & 0.00 & $297,229.9$ & $297,229.9$ \\
\hline Surveillance & 0.00 & $291,974.5$ & $291,974.5$ \\
\hline Epithelial ovarian cancer management & $10,918,562.8$ & $10,846,439.4$ & $-72,123.4$ \\
\hline Breast cancer treatment & $680,468.2$ & $468,388.46$ & $-212,079.8$ \\
\hline Palliative care & $454,260.1$ & $434,403.7$ & $-19,856.4$ \\
\hline Total cost & $12,053,291.2$ & $13,437,897.4$ & $1,384,606.3$ \\
\hline \multicolumn{4}{|l|}{ QALYs } \\
\hline Patients & 328.4 & 328.4 & 0 \\
\hline Relatives & 1735.6 & 1779.4 & 43.8 \\
\hline Global & 2064 & 2107.8 & 43.8 \\
\hline ICUR & $€ 31,621.3 / \mathrm{QALY}$ & & \\
\hline
\end{tabular}

QALYs quality-adjusted life years, ICUR incremental cost-utility ratio their relatives amounted to $€ 13,437,897.43$, while the notesting scenario accounted for $€ 12,053,291.17$ (difference $€ 1,384,606.26)$; the ICUR associated with the germline BRCA1/2 testing is $€ 31,621.33 / \mathrm{Q} A L Y$.

Although there is no established cost-utility threshold for screening tests in Spain, several thresholds have been applied in other European studies. In Belgium, Pil, et al. [38] used a €35,000/QALY threshold, while D'Andrea et al. [39] and Areia et al. [40] set a threshold of €37,000/QALY in Italy and Portugal, respectively. However, Neuman et al.
[41] and Naber et al. [42] considered a higher cost-utility threshold ( $€ 50,000 / \mathrm{Q} A L Y$ ). According to the cost-utility thresholds used in these studies, providing a germline BRCA $1 / 2$ testing to HGEOC patients without family history of $\mathrm{OC}$ or $\mathrm{BC}$ and their gBRCA $1 / 2 \mathrm{~m}$-positive relatives is cost-effective in Spain. Our results of the one-way sensitivity analyses were not substantially different from the base case, and most of them were below the $€ 37,000 / \mathrm{QALY}$ threshold. Besides, our PSA showed that $52.52 \%$ of our simulations fell below the $€ 35,000 / \mathrm{QALY}$ threshold, $60.56 \%$ were below 
Table 4 One-way sensitivity analysis results

\begin{tabular}{|c|c|c|c|c|c|c|}
\hline & \multicolumn{3}{|l|}{ Lower case } & \multicolumn{3}{|l|}{ Upper case } \\
\hline & Costs & QALYs & ICUR & Costs & QALYs & ICUR \\
\hline Age of the patients $( \pm 10 \%)$ & $€ 1,099,026.04$ & 74.80 & $€ 14,692.37$ & $€ 1,371,276.88$ & 36.47 & $€ 37,596.55$ \\
\hline Risk of cancer in BRCA1/2 carriers $( \pm 25 \%)$ & $€ 1,216,114.09$ & 32.23 & $€ 37,737.92$ & $€ 1,619,241.65$ & 66.57 & $€ 24,322.18$ \\
\hline Uptake rate of preventive surgery $( \pm 25 \%)$ & $€ 1,355,678.48$ & 40.81 & $€ 33,216.02$ & $€ 1,425,406.95$ & 44.60 & $€ 31,960.17$ \\
\hline Costs of tests and management of cancer $( \pm 10 \%)$ & $€ 1,244,501.58$ & 43.79 & $€ 28,421.65$ & $€ 1,524,710.95$ & 43.79 & $€ 34,821.00$ \\
\hline Cancer risk after preventive surgery $(\mathrm{HR})( \pm 25 \%)$ & $€ 1,384,606.26$ & 43.79 & $€ 31,621.33$ & $€ 1,415,731.82$ & 39.26 & $€ 36,060.67$ \\
\hline Cancer utilities $( \pm 10 \%)$ & $€ 1,384,606.26$ & 47.38 & $€ 29,222.77$ & $€ 1,384,606.26$ & 40.19 & $€ 34,448.82$ \\
\hline
\end{tabular}

$H R$ hazard ratio, $Q A L Y s$ quality-adjusted life years, ICUR incremental cost-utility ratio

(a)

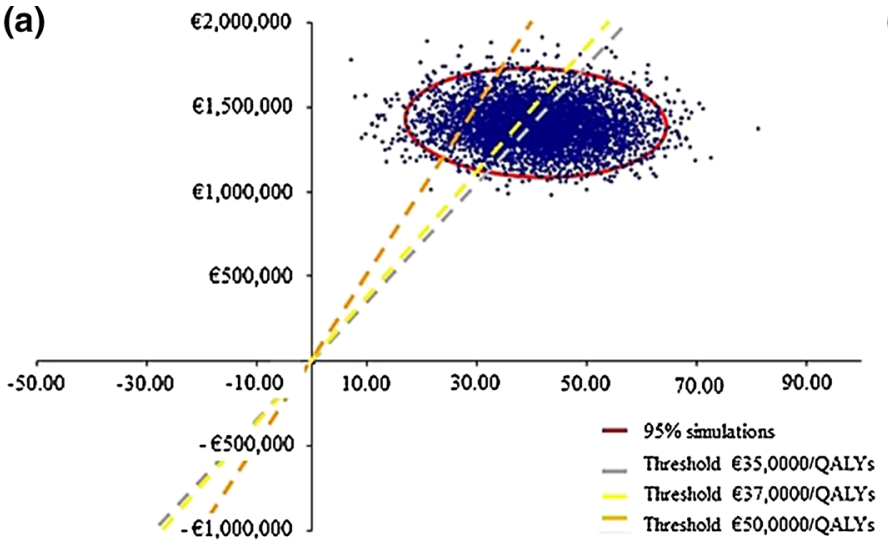

(b)

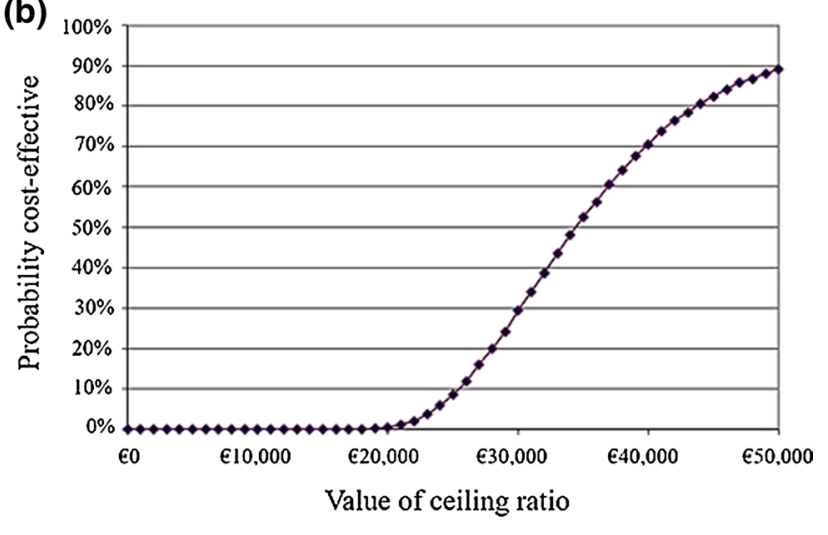

Fig. 2 Probabilistic sensitivity analysis. a cost-effectiveness plane b willingness-to-pay curve.

$Q A L Y$ quality-adjusted life years

the $€ 37,000 / \mathrm{QALY}$ threshold, and $89.12 \%$ were below the $€ 50,000 / \mathrm{QALY}$ threshold [38-42].

Cost-utility studies about providing RRS to gBRCA1/2m carriers have been previously analyzed in other countries. Müller et al. evaluated the cost-effectiveness of providing $\mathrm{BM}$ and $\mathrm{BSO}$ to women who were gBRCA1/2m carriers in Germany. Their results showed that providing both RRS at age 30 is more cost-effective ( $€ 1662.94 / \mathrm{QALY})$ than offering BM and BSO at age 40 ( $€ 1782.99 / \mathrm{QALY})$. Both RRS at age 30 are also more cost-effective than providing each of the surgeries alone (€2082.70/QALY for BSO and $€ 2292.99 / \mathrm{Q} A L Y$ for BM) or providing the surveillance strategy (€3040.11/QALY) [43]. However, our results include the resources of identifying a target population with high risk of cancer, as well as the cancer management of the gBRCA $1 / 2 \mathrm{~m}$ carriers (despite having undergone RRS) during 50 years; hence, they cannot be directly compared. In line with our study, Eccleston et al. [11] showed that the ICUR of providing germline BRCA1/2 testing to EOC patients and their relatives, along with the subsequent management of the relatives with gBRCA1/2m, was $£ 4339$ / QALY in UK. Although our research followed the same methodology developed by Eccleston et al., we considered a different study population and higher screening and surveillance tests, according to the Spanish guidelines [7, 9]; therefore, our results cannot be directly compared.

Our study has limitations. First, due to the lack of information on epidemiology variables, genetic testing, and $\mathrm{BC}$ and EOC management in Spain, data related to other countries had to be included in the simulation. Second, the simulation considered the cost of $\mathrm{BC}$ management only in the first year after the diagnosis. However, as BC may last several years, including the costs from the following years would imply an increase in global costs, which would decrease the final ICUR. Third, the adverse events due to the cancer treatment have not been considered in the simulation; including the cost of the adverse events management would decrease the global cost of the cancer treatment, which would reduce the final ratio. Four, due to the lack of utility values in patients with EOC and/or BC in Spain, we assumed those of the UK population. Since all these limitations may have an impact on our results, the base-case values were varied in the one-way sensitivity analyses and the PSA and the corresponding results were compared to the cost-utility threshold (Table 5, Online Resources).Despite these limitations, the main contribution of this study is the economic 
evaluation of a screening test provided to a well-defined population. From our knowledge, this is the first study that evaluates the cost-utility of providing germline BRCA testing to HGEOC patients without family history of $\mathrm{OC}$ or $\mathrm{BC}$ and their relatives. Genetic testing to HGEOC patients allows registering patients with hereditary cancer that may transmit gBRCA $1 / 2 \mathrm{~m}$ to their descendants, and, therefore, may be useful for designing effective public health programmes against cancer to the target population. As was shown in the Ovarcost study, investing in techniques for early diagnosis may imply higher survival rates and a substantial reduction in the economic burden of cancer, due to possible cost savings at advanced disease stages [26]. It is worth noting that if all gBRCA1/2m carriers accepted to undergo RRS, the number of BC and EOC patients would be decreased and that the ICUR of the germline BRCA $1 / 2$ testing would be lower than our base-case result (€31,621.33/QALY). It should also be noted that the simulation did not consider other benefits that germline BRCA1/2 testing may have on patients, such as providing information on the most appropriate therapy choice [9]. Besides, healthy gBRCA1/2m carriers who choose not to undergo RRS would still receive surveillance visits and tests that may imply higher benefits like earlier diagnosis of cancer, which may turn out in higher overall and disease-free survival rates $[9,26]$.

\section{Conclusions}

Our results showed that the germline BRCA1/2 testing in HGEOC patients without family history and their relatives is cost-effective, according to the European thresholds commonly used ( $€ 35,000-€ 50,000 / \mathrm{Q} A L Y)$, with an ICUR of $€ 31,621.33 / \mathrm{QALY}$.

The simulation results showed that providing germline BRCA $1 / 2$ testing to those patients and their relatives allows one to identify a target population with high risk of cancer, to provide effective prevention strategies. Besides, the decrease in the number of patients diagnosed with $\mathrm{BC}$ and EOC would shorten management costs, and reduce mortality rates of those cancers. In conclusion, investment in screening techniques would improve the disease-free survival rates of those patients. Early diagnosis techniques are able to reduce the burden of cancer, as they decrease the costs of the therapeutics and improve the quality of life of patients.

Funding This study was funded by AstraZeneca Farmaceutica Spain.

\section{Compliance with ethical standards}

Conflict of interest Authors Carlota Moya-Alarcón and Susana Simon are employees of AstraZeneca Farmaceutica Spain. Authors Almud- ena Gonzalez-Domínguez and Ines Perez-Roman work in Weber, enterprise that received fees from AstraZenena Farmaceutica Spain. Authors Antonio Gonzalez-Martín, Eloísa Bayo-Lozano and Ana Beatriz Sánchez-Heras have participated as experts for Weber, enterprise that received consulting fees from AstraZeneca Farmaceutica Spain.

Research involving human participants and/or animals This article does not contain any studies with human participants or animals performed by any of the authors.

Informed Consent Informed Consent is not required for this type of study.

OpenAccess This article is distributed under the terms of the Creative Commons Attribution 4.0 International License (http://creativeco mmons.org/licenses/by/4.0/), which permits unrestricted use, distribution, and reproduction in any medium, provided you give appropriate credit to the original author(s) and the source, provide a link to the Creative Commons license, and indicate if changes were made.

\section{References}

1. Galceran J, Ameijide A, Carulla M, Mateos A, Quirós JR, Rojas D, et al. Cancer incidence in Spain, 2015. Clin Transl Oncol. 2017;19:799-825.

2. Sociedad Española de Oncología Médica (SEOM). Las cifras del cáncer en España 2018. 2018.

3. Matz M, Coleman MP, Carreira H, Salmerón D, Chirlaque MD, Allemani C. Worldwide comparison of ovarian cancer survival: Histological group and stage at diagnosis (CONCORD-2). Gynecol Oncol. 2017;144:396-404.

4. Liede A, Karlan BY, Narod SA. Cancer risks for male carriers of germline mutations in BRCA1 or BRCA2: a review of the literature. J Clin Oncol. 2004;22:735-42.

5. Rebbeck TR, Mitra N, Wan F, Sinilnikova OM, Healey S, McGuffog L, et al. Association of type and location of BRCA1 and BRCA2 mutations with risk of breast and ovarian cancer. JAMA. 2015;313:1347.

6. Mavaddat N, Peock S, Frost D, Ellis S, Platte R, Fineberg E, et al. Cancer risks for BRCA1 and BRCA2 mutation carriers: results from prospective analysis of EMBRACE. JNCI J Natl Cancer Inst. 2013;105:812-22.

7. Graña B, Lastra E, Llort G, Brunet J, Isla D. SEOM clinical guidelines for hereditary cancer. Clin Transl Oncol. 2011;13:580.

8. Alsop K, Fereday S, Meldrum C, deFazio A, Emmanuel C, George $\mathrm{J}$, et al. BRCA mutation frequency and patterns of treatment response in BRCA mutation-positive women with ovarian cancer: a report from the Australian Ovarian Cancer Study Group. J Clin Oncol. 2012;30:2654-63.

9. Llort G, Chirivella I, Morales R, Serrano R, Sanchez AB, Teulé $\mathrm{A}$, et al. SEOM clinical guidelines in hereditary breast and ovarian cancer. Clin Transl Oncol. 2015;17:956.

10. Paluch-Shimon S, Cardoso F, Sessa C, Balmana J, Cardoso MJ, Gilbert F, et al. Prevention and screening in BRCA mutation carriers and other breast/ovarian hereditary cancer syndromes: ESMO clinical practice guidelines for cancer prevention and screening. Ann Oncol. 2016;27:v103-10.

11. Eccleston A, Bentley A, Dyer M, Strydom A, Vereecken W, George A, et al. A cost-effectiveness evaluation of germline BRCA1 and BRCA2 testing in UK women with ovarian cancer. Value Health. 2017;20:567-76. 
12. Gabaldó Barrios X, Sarabia Meseguer MD, Marín Vera M, Sánchez Bermúdez AI, Macías Cerrolaza JA, Sánchez Henarejos $\mathrm{P}$, et al. Molecular characterization and clinical interpretation of BRCA1/BRCA2 variants in families from Murcia (south-eastern Spain) with hereditary breast and ovarian cancer: clinical-pathological features in BRCA carriers and non-carriers. Fam Cancer. 2017;16:477-89.

13. Evolución del test genético de BRCA1 y BRCA2 en pacientes con cáncer de mama u ovario a lo largo de una década. SEOM 2015. 2015. http://www.postersessiononline.es/312191188_es/congr esos/15seom/aula/-P_192_15seom.pdf. Accessed 25 Oct 2017.

14. Chirlaque MD, Salmerón D, Ardanaz E, Galceran J, Martínez R, Marcos-Gragera R, et al. Cancer survival in Spain: estimate for nine major cancers. Ann Oncol. 2010;21:iii21-9.

15. Instituto Nacional de Estadistica. (Spanish Statistical Office). http://www.ine.es/en/welcome.shtml. Accessed 7 Jun 2018.

16. Petrucelli N, Daly MB, Pal T. BRCA1- and BRCA2-associated hereditary breast and ovarian cancer. In: Adam MP, Ardinger HH, Pagon RA, Wallace SE, Bean LJ, Stephens K, et al., editors. GeneReviews ${ }^{\circledR}$. Seattle: University of Washington; 2016. http:// www.ncbi.nlm.nih.gov/books/NBK1247/. Accessed 22 Mar 2018.

17. Alonso-Babarro A, Bruera E, Varela-Cerdeira M, Boya-Cristia MJ, Madero R, Torres-Vigil I, et al. Can this patient be discharged home? Factors associated with at-home death among patients with cancer. J Clin Oncol. 2011;29:1159-67.

18. Bennett MI, Ziegler L, Allsop M, Daniel S, Hurlow A. What determines duration of palliative care before death for patients with advanced disease? A retrospective cohort study of community and hospital palliative care provision in a large UK city. BMJ Open. 2016;6:e012576.

19. Alonso-Babarro A, Astray-Mochales J, Dominguez-Berjon F, Genova-Maleras R, Bruera E, Diaz-Mayordomo A, et al. The association between in-patient death, utilization of hospital resources and availability of palliative home care for cancer patients. Palliat Med. 2013;27:68-75.

20. Ministerio de Sanidad, Servicios Sociales e Igualdad. Instituto de Información Sanitaria. Registro de altas. 2015.

21. Gómez-Batiste X, Porta-Sales J, Espinosa-Rojas J, Pascual-López A, Tuca A, Rodriguez J. Effectiveness of palliative care services in symptom control of patients with advanced terminal cancer: a Spanish, multicenter, prospective, quasi-experimental, pre-post study. J Pain Symptom Manag. 2010;40:652-60.

22. Alonso-Babarro A, Varela-Cerdeira M, Torres-Vigil I, RodríguezBarrientos R, Bruera E. At-home palliative sedation for end-oflife cancer patients. Palliat Med. 2010;24:486-92.

23. Calvo-Espinos C, Ruiz de Gaona E, Gonzalez C, Ruiz de Galarreta L, Lopez C. Palliative sedation for cancer patients included in a home care program: a retrospective study. Palliat Support Care. 2014;13:619-24.

24. Mediana de los costes de los Boletines Oficiales de las Comunidades Autónomas. 2017.

25. Bastida JL, Oliva J, Antoñanzas F, García-Altés A, Gisbert R, Mar $\mathrm{J}$, et al. Propuesta de guía para la evaluación económica aplicada a las tecnologías sanitarias. Gac Sanit. 2010;24:154-70.

26. Delgado-Ortega L, González-Domínguez A, Borras J, Oliva J, González-Haba E, Menjón S, et al. The economic burden of disease of epithelial ovarian cancer in Spain. The Ovarcost Study. Eur J Health Econ. 2018. https://doi.org/10.1007/s10198-018-0986-y.

27. García-Gutierrez S, Sarasqueta C, Legarreta MJ, Gonzalez N, Redondo M, Rivero A, et al. Health services research in patients with breast cancer (CAMISS-prospective): study protocol for an observational prospective study. BMC Cancer. 2018;18:54.

28. Arrospide A, Soto-Gordoa M, Acaiturri T, López-Vivanco G, Abecia LC, Mar J. Cost of breast cancer treatment by clinical stage in the Basque Country, Spain. Rev Esp Salud Pública. 2015;89:93-7.
29. Luengo-Fernandez R, Leal J, Gray A, Sullivan R. Economic burden of cancer across the European Union: a population-based cost analysis. Lancet Oncol. 2013;14:1165-74.

30. Agencia Española de Medicamentos y Productos Sanitarios (AEMPS). Ficha Técnica Arimidex $1 \mathrm{mg}$ comprimidos recubiertos con película. 2014. In: AEMPS. https://cima.aemps.es/cima/ dochtml/ft/61286/FT_61286.html. Accessed 19 Feb 2018.

31. Havrilesky LJ, Broadwater G, Davis DM, Nolte KC, Barnett JC, Myers ER, et al. Determination of quality of life-related utilities for health states relevant to ovarian cancer diagnosis and treatment. Gynecol Oncol. 2009;113:216-20.

32. Peasgood T, Ward SE, Brazier J. Health-state utility values in breast cancer. Expert Rev Pharmacoecon Outcomes Res. 2010;10:553-66.

33. National Institute for Clinical Excellence (NICE). Cost-effectiveness evidence review. Familial breast cancer: classification and care of women at risk of familial breast cancer and management of breast cancer and related risk in people with a family history of breast cancer. 2013.

34. Kind P, Hardman G, Macran S. UK population norms for EQ-5D. In: Centre for Health Economics, University of York; 1999. https ://econpapers.repec.org/paper/chyrespap/172chedp.htm. Accessed 29 Aug 2018.

35. Grann VR, Patel PR, Jacobson JS, Warner E, Heitjan DF, AshbyThompson M, et al. Comparative effectiveness of screening and prevention strategies among BRCA1/2-affected mutation carriers. Breast Cancer Res Treat. 2011;125:837-47.

36. Halbert CH, Stopfer JE, McDonald J, Weathers B, Collier A, Troxel AB, et al. Long-term reactions to genetic testing for BRCA1 and BRCA2 mutations: Does time heal women's concerns? J Clin Oncol. 2011;29:4302-6.

37. Sie AS, Spruijt L, van Zelst-Stams WAG, Mensenkamp AR, Ligtenberg MJL, Brunner HG, et al. High satisfaction and low distress in breast cancer patients one year after BRCA-mutation testing without prior face-to-face genetic counseling. J Genet Couns. 2016;25:504-14.

38. Pil L, Hoorens I, Vossaert K, Kruse V, Tromme I, Speybroeck N, et al. Cost-effectiveness and budget effect analysis of a populationbased skin cancer screening. JAMA Dermatol. 2017;153:147-53.

39. D'Andrea E, Marzuillo C, Pelone F, Vito CD, Villari P. Genetic testing and economic evaluations: a systematic review of the literature. Epidemiol Prev. 2015;39:45-50.

40. Areia M, Spaander MC, Kuipers EJ, Dinis-Ribeiro M. Endoscopic screening for gastric cancer: a cost-utility analysis for countries with an intermediate gastric cancer risk. United Eur Gastroenterol J. 2018;6:192-202.

41. Neumann A, Lindholm L, Norberg M, Schoffer O, Klug SJ, Norström F. The cost-effectiveness of interventions targeting lifestyle change for the prevention of diabetes in a Swedish primary care and community based prevention program. Eur J Health Econ. 2017;18:905-19.

42. Naber SK, Matthijsse SM, Rozemeijer K, Penning C, de Kok IMCM, van Ballegooijen M. Cervical cancer screening in partly HPV vaccinated cohorts-a cost-effectiveness analysis. PLoS ONE. 2016;11:e0145548.

43. Müller D, Danner M, Rhiem K, Stollenwerk B, Engel C, Rasche $\mathrm{L}$, et al. Cost-effectiveness of different strategies to prevent breast and ovarian cancer in German women with a BRCA 1 or 2 mutation. Eur J Health Econ. 2017. https://doi.org/10.1007/s1019 8-017-0887-5.

Publisher's Note Springer Nature remains neutral with regard to jurisdictional claims in published maps and institutional affiliations. 